\title{
Base Isolation Seismic Retrofit of a Hospital Building in
}

\section{Italy}

\author{
Massimiliano Ferraioli and Alberto Maria Avossa \\ Department of Civil Engineering, Second University of Naples, via Roma 29, 81031, Aversa, CE, Italy
}

\begin{abstract}
The paper deals on a significant retrofit project currently under construction of an existing hospital building in Avellino (Italy). The seismic retrofit was realized by connecting together the first floors of the three existing structures and by creating a unique isolation system composed of high damping rubber bearings and sliding devices. The base isolation is achieved by gradually cutting the building from foundation and installing the isolators at the level of upper edge of the columns. The study allows the verification of the adequacy of the isolation system, showing the benefits of the application of the isolation devices, the limitations and the characteristics of their performance.
\end{abstract}

Key words: Seismic retrofit, base isolation, seismic response.

\section{Introduction}

Most of the existing buildings are vulnerable to earthquakes because they are gravity load designed or are designed with earlier codes to withstand seismic action of low intensity. Many of these constructions with low lateral load resisting capacity are located in high seismic hazard areas and so they represent a significant risk to life during earthquakes, especially because many of them are school or hospital buildings. Recently, a new interest in the application of seismic isolation has been caused by the recent strong Italian earthquakes (Umbria-Marche, 1997; Molise-Puglia, 2002; Abruzzo, 2009) and by the editing of the new Italian Code [1]. In fact, like Eurocode 8 [2, 3], the Italian code contains two chapters devoted to seismic isolation of buildings and bridges respectively, and this had a great effect in order to promote the general application of seismic isolation not only for schools, emergency management centers, hospitals and so on, but also in the field of the ordinary residential and commercial buildings. On the other side, the traditional

Corresponding author: Massimiliano Ferraioli, $\mathrm{PhD}$, assistant professor, research fields: structural engineering. E-mail: massimiliano.ferraioli@unina2.it. methods of seismic retrofitting based on the increase of the structural capacity may have problems of convergence. In fact, in general these approaches tend to increase not only strength and ductility, but also lateral stiffness. The consequent period shortening of the structure generally increases the seismic demand except in the case of low-rise buildings that fail in the constant-acceleration region of the response spectrum. It is worth noting that seismic isolation and energy dissipation are certainly convenient also from an economical point of view, especially in the case of strategic structures for which the return period of the design seismic event should be very long and the structure will probably suffer many strong earthquakes during its life time. Seismic isolation appears to be the most appropriate solution, which allows the seismic behaviour of the hospital building to comply the provisions of the Italian Code. The key objective of this paper is to present the base isolation retrofit design of a hospital building in Avellino that will ensure cost-effectiveness of the construction works and high reliability of the structure. 


\section{Seismic Risk Assessment of Existing Building}

\subsection{General Description}

The case study is a 5-storey hospital building located in the new hospital campus of Avellino in Campania (Italy). This building was composed of 3 reinforced concrete moment resisting frame structures (Figs. 1-2) designed after the Irpino-Lucano earthquake of 1980 according to the old Italian Seismic Code. In particular, depending on the seismicity of the site, this code classified Avellino as II category zone (maximum value of horizontal design spectral acceleration $\mathrm{S}_{\mathrm{a}}=$ $0.07 \mathrm{~g}$ ) and prescribed an occupancy importance factor $\mathrm{I}=1.40$.

The building was designed using response spectrum analysis and working stress method. For the structure A the cross section is $35 \times 60$ for beams, $50 \times 70$ for first floor columns, $35 \times 70$ for other columns. For the structures $\mathrm{B}$ and $\mathrm{C}$ the cross section is $35 \times 70$ for columns, $45 \times 60$ for first floor beams and $35 \times 60$ for other beams. The foundations have an inverted T-shaped cross-section (height $=130 \mathrm{~cm}$, flange thickness $=40 \mathrm{~cm}$; flange width $=145 \mathrm{~cm}$; web thickness $=110 \mathrm{~cm}$ in dilatation joint and $60 \mathrm{~cm}$ otherwise) and connect together the three superstructures. The reinforced concrete retaining walls are disconnected from both structures in elevation and foundations. The floors are made up of mixed reinforced concrete and hollow tiles with thickness equal to $16+5 \mathrm{~cm}$. The characteristic value is $5.80 \mathrm{kN} / \mathrm{m}^{2}$ for permanent loads, and $3.00 \mathrm{kN} / \mathrm{m}^{2}$ for imposed loads. As far as structural details, the spacing of steel stirrups is $10 \mathrm{~cm}$ in the critical regions and $20 \mathrm{~cm}$ otherwise for both columns and beams.

The construction of the building was never completed, and only the structural members were realized. However, the evolution of seismic codes in Italy after the recent Italian earthquakes produced a general increase of the design seismic actions. As a consequence, rehabilitation and retrofit were required for seismic upgrading of the existing structures.

\subsection{Material Survey}

Both destructive and non-destructive testing methods were used for the building diagnosis-state. In particular, 12 monotonic compressive tests on cylindrical specimens, 18 tensile tests on steel rebars,

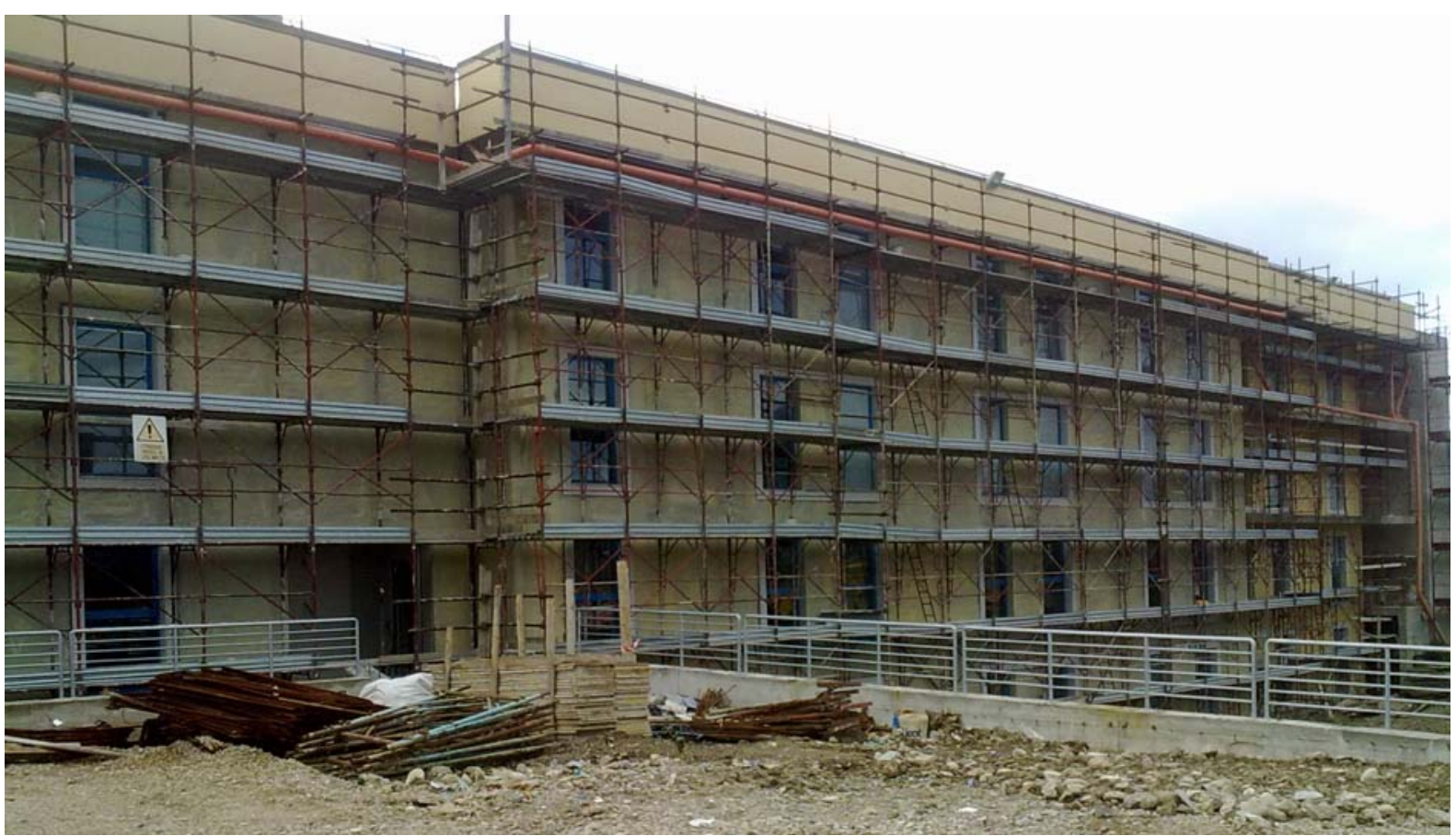

Fig. 1 View of the hospital building in Avellino. 


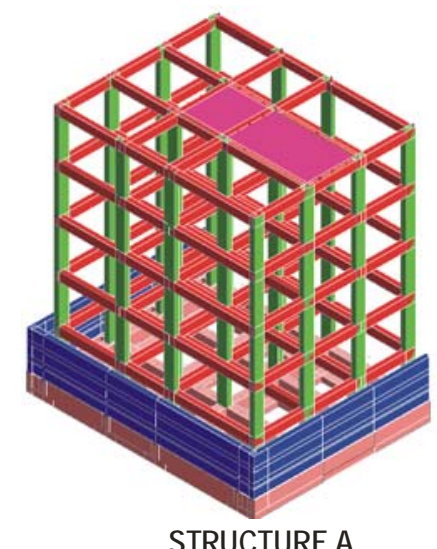

STRUCTUREA

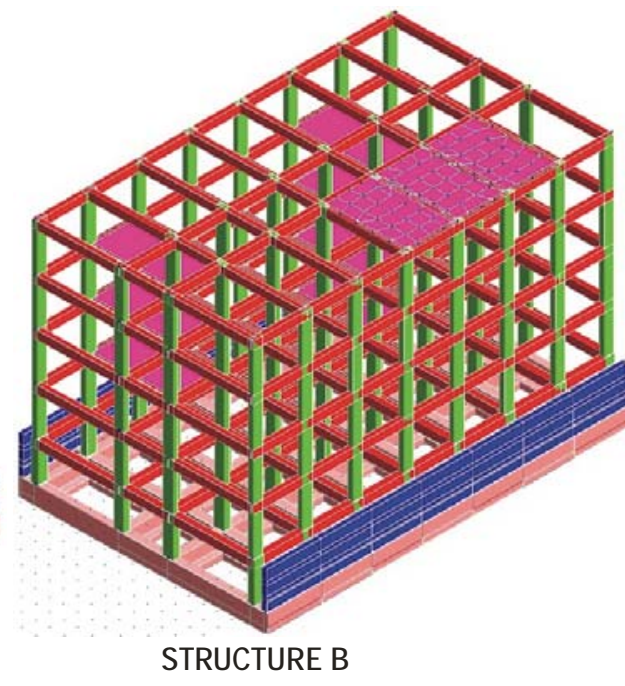

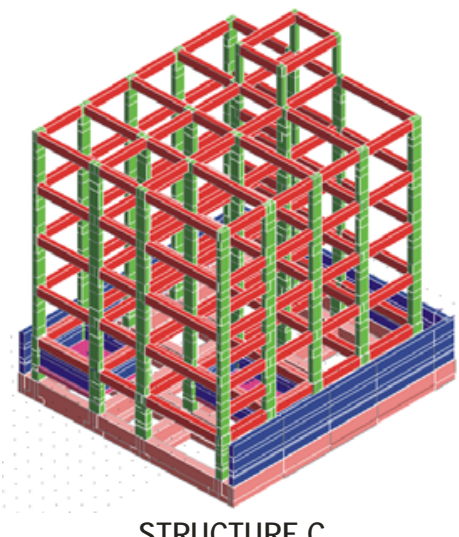

STRUCTURE C

Fig. 2 Models of existing structures.

46 ultrasonic tests combined with Schmidt rebound hammer tests and, finally, radiographic tests were carried out. The mean value of the compressive strength of concrete is $f_{c m}=39.86 \mathrm{MPa}$ (minimum value $=33.32$, maximum value $=50.58$, standard deviation $=4.967$, coefficient of variation $=0.1246$ ) . The mean value from the combined Sonreb method is 38.45 MPa. It is worth noting that the design value of concrete compressive strength is $\mathrm{R}_{\mathrm{ck}}=25.0 \mathrm{MPa}$. The mean value of tensile strength of steel rebars is $f_{y m}=$ $563 \mathrm{MPa}$ (minimum $=484.07$, maximum $=559.61$, standard deviation $=23.22$, coefficient of variation $=$ 0.0441). For the calculation of the capacities of elements the mean value properties of the existing materials are used, appropriately divided by the Confidence Factor (CF) accounting for the level of knowledge attained. In particular, in the case study a full Knowledge Level (KL3 according to Eurocode 8) was obtained. Finally, geological and geotechnical tests were carried out to evaluate the soil profile and to determine the ground type according to Eurocode 8 and Italian Code. In particular, the following in-situ tests were performed: N.6 soil profile tests, N.5 Standard Penetration Tests (SPT) and N.1 Down-hole Test which determines soil stiffness properties by analyzing direct compression and shear waves along a borehole down to $30 \mathrm{~m}$. According to results the soil shall be classified as Type B.

\subsection{Structural Model and Seismic Hazard}

A necessary activity that must precede the seismic rehabilitation program is the seismic vulnerability assessment of the existing building and the identification of its specific deficiencies. The vulnerability evaluation, for what concerns in particular seismic action, performance levels and mechanical properties of materials, was performed according to new Italian Seismic Code [1]. In this document four performance levels are considered: Operational Limit State (SLO), Damage Limit State (SLD), Life Safety Limit State (SLV), Collapse Prevention Limit State (SLC). The parameters of the elastic response spectra are reported in Table 1. The floor diaphragms of the buildings have sufficient in-plane stiffness to be taken as being rigid in their planes. Furthermore, the high strength and stiffness of the foundation allow the foundation-structure interaction to be neglected. As consequence, the analyses were carried out considering columns restrained against vertical and horizontal displacements.

In Tables $2-4$ the natural periods, the spectral horizontal accelerations for the different limit states, and the modal mass ratios $\mathrm{X}$ and $\mathrm{Y}$ are evidenced. The range of natural periods of the structures is between 0.506 and $0.605 \mathrm{sec}$. A nonlinear model based on 
concentrated plasticity (coupled PMM hinge model) was implemented in a finite element computer program (SAP2000 [4]). A bilinear moment-rotation curve was considered for the plastic hinges. The yielding, the ultimate bending moment and the ultimate hinge rotation were characterized according to the Italian Code Provisions [1].

\subsection{Seismic Risk Assessment}

The seismic performance evaluation of the hospital building was carried out with a nonlinear static procedure based on pushover analysis. The validity and applicability of this nonlinear static procedure have been extensively studied in literature. Different Nonlinear Static Procedures (NSPs) based on the Capacity Spectrum Method (CSM) or on the Coefficient Method (CM) have been introduced in pre-standards reports and guidelines (Italian Code 2008 [1], Eurocode 8 [2], ATC-40 [5], Italian Ordinance 3274 [6]; FEMA 440 ATC-55 [7]). In this paper, the procedure defined in Eurocode 8 is used for the analyses. In particular, the structure is pushed statically to a target displacement at the control node to check for the acceptable structural performance. Different height-wise distributions of lateral loads are usually considered. In fact, the shear forces vs. story drift relationship may be very sensitive to the applied load pattern. In this paper, according to the Italian Code, two different distributions of lateral load are applied: (1) Fundamental Mode Distribution (FMD): the vertical distribution is proportional to the floor masses and the fundamental mode shape; (2) Uniform Distribution (UD): the lateral load distribution is proportional to the floor masses. An accidental eccentricity of 5 percent of planar dimensions is considered in the analysis. The target displacement is determined from the elastic demand response spectrum and the capacity curve according to the procedure reported in Annex B of EC8 and in Italian Code. The procedure is based on an idealized elasto-perfectly plastic force-displacement relationship and on an equivalent linearization. Pushover analysis (Figs. 3a-3c) gives the target displacements for the limit states SLO, SLD and SLV and the corresponding values of the peak ground acceleration $\left(P G A_{S L O}^{C} ; P G A_{S L D}^{C} ; P G A_{S L V}^{C} ; P G A_{S L C}^{C}\right)$ that represents the actual capacity of the structure.

The seismic demand is defined by the peak ground accelerations for the different limit states $\left(P G A^{d}{ }_{S L O}\right.$; $\left.P G A^{d}{ }_{S L D} ; P G A_{S L V}^{d} ; P G A^{d}{ }_{S L C}\right)$. Finally, the risk indices are defined by the following demand/capacity quotients:

$$
\begin{aligned}
& \alpha_{S L O}=\frac{P G A_{S L O}^{c}}{P G A_{S L O}^{d}}, \quad \alpha_{S L D}=\frac{P G A_{S L D}^{c}}{P G A_{S L D}^{d}}, \\
& \alpha_{S L V}=\frac{P G A_{S L V}^{c}}{P G A_{S L V}^{d}}, \quad \alpha_{S L C}=\frac{P G A_{S L C}^{c}}{P G A_{S L C}^{d}}
\end{aligned}
$$

Table 1 Elastic response spectra in terms of horizontal acceleration for different Limit States (SLO, SLD, SLV, SLC).

\begin{tabular}{ccccc}
\hline Parameter & SLO & SLD & SLV & SLC \\
\hline Probability of excedence $\mathrm{P}_{\mathrm{VR}}$ & 0.81 & 0.63 & 0.10 & 0.05 \\
Return Period $\mathrm{T}_{\mathrm{R}}$ (years) & 120 & 201 & 1898 & 2475 \\
Peak ground acceleration $\mathrm{a}_{\mathrm{g}} / \mathrm{g}$ & 0.109 & 0.139 & 0.318 & 0.345 \\
Amplification factor $\mathrm{F}_{\mathrm{o}}$ & 2.346 & 2.350 & 2.470 & 2.489 \\
Transition Period $\mathrm{T}_{\mathrm{C}}(\mathrm{sec})$ & 0.336 & 0.350 & 0.398 & 0.406 \\
\hline
\end{tabular}

Table 2 Dynamic properties of structure A.

\begin{tabular}{cccccccc}
\hline Mode & $\begin{array}{c}\text { Period } \\
(\mathrm{sec})\end{array}$ & $\begin{array}{c}\mathrm{S}_{\mathrm{a}} / \mathrm{g} \\
(\mathrm{SLO})\end{array}$ & $\begin{array}{c}\mathrm{S}_{\mathrm{a}} / \mathrm{g} \\
(\mathrm{SLD})\end{array}$ & $\begin{array}{c}\mathrm{S}_{\mathrm{a}} / \mathrm{g} \\
(\mathrm{SLV})\end{array}$ & $\begin{array}{c}\mathrm{S}_{\mathrm{a}} / \mathrm{g} \\
(\mathrm{SLC})\end{array}$ & $\begin{array}{c}\mathrm{M}_{\mathrm{x}, \mathrm{n}}^{*} / \mathrm{M}_{\text {tot }} \\
(\%)\end{array}$ & $\begin{array}{c}\mathrm{M}^{*}{ }_{\mathrm{y}, \mathrm{n}} / \mathrm{M}_{\text {tot }} \\
(\%)\end{array}$ \\
\hline 1 & 0.605 & 0.233 & 0.308 & 0.238 & 0.802 & 75.99 & 0.89 \\
2 & 0.574 & 0.246 & 0.324 & 0.251 & 0.846 & 1.69 & 72.27 \\
3 & 0.496 & 0.285 & 0.375 & 0.273 & 0.907 & 1.31 & 6.10 \\
4 & 0.181 & 0.307 & 0.392 & 0.273 & 0.907 & 10.63 & 0.16 \\
5 & 0.174 & 0.307 & 0.392 & 0.274 & 0.894 & 0.27 & 10.16 \\
\hline
\end{tabular}


Table 3 Dynamic properties of structure B.

\begin{tabular}{cccccccc}
\hline Mode & $\begin{array}{c}\text { Period } \\
(\mathrm{sec})\end{array}$ & $\begin{array}{c}\mathrm{S}_{\mathrm{a}} / \mathrm{g} \\
(\mathrm{SLO})\end{array}$ & $\begin{array}{c}\mathrm{S}_{\mathrm{a}} / \mathrm{g} \\
(\mathrm{SLD})\end{array}$ & $\begin{array}{c}\mathrm{S}_{\mathrm{a}} / \mathrm{g} \\
(\mathrm{SLV})\end{array}$ & $\begin{array}{c}\mathrm{S}_{\mathrm{a}} / \mathrm{g} \\
(\mathrm{SLC})\end{array}$ & $\begin{array}{c}\mathrm{M}_{\mathrm{x}, \mathrm{n}}^{*} / \mathrm{M}_{\mathrm{tot}} \\
(\%)\end{array}$ & $\begin{array}{c}\mathrm{M}_{\mathrm{y}, \mathrm{n}}^{*} / \mathrm{M}_{\mathrm{tot}} \\
(\%)\end{array}$ \\
\hline 1 & 0.555 & 0.254 & 0.335 & 0.259 & 0.874 & 0.04 & 76.22 \\
2 & 0.530 & 0.266 & 0.351 & 0.272 & 0.907 & 71.16 & 0.08 \\
3 & 0.467 & 0.302 & 0.392 & 0.273 & 0.907 & 5.42 & 0.07 \\
4 & 0.170 & 0.307 & 0.392 & 0.276 & 0.882 & 0.00 & 11.52 \\
5 & 0.165 & 0.307 & 0.392 & 0.278 & 0.866 & 10.65 & 0.00 \\
\hline
\end{tabular}

Table 4 Dynamic properties of structure C.

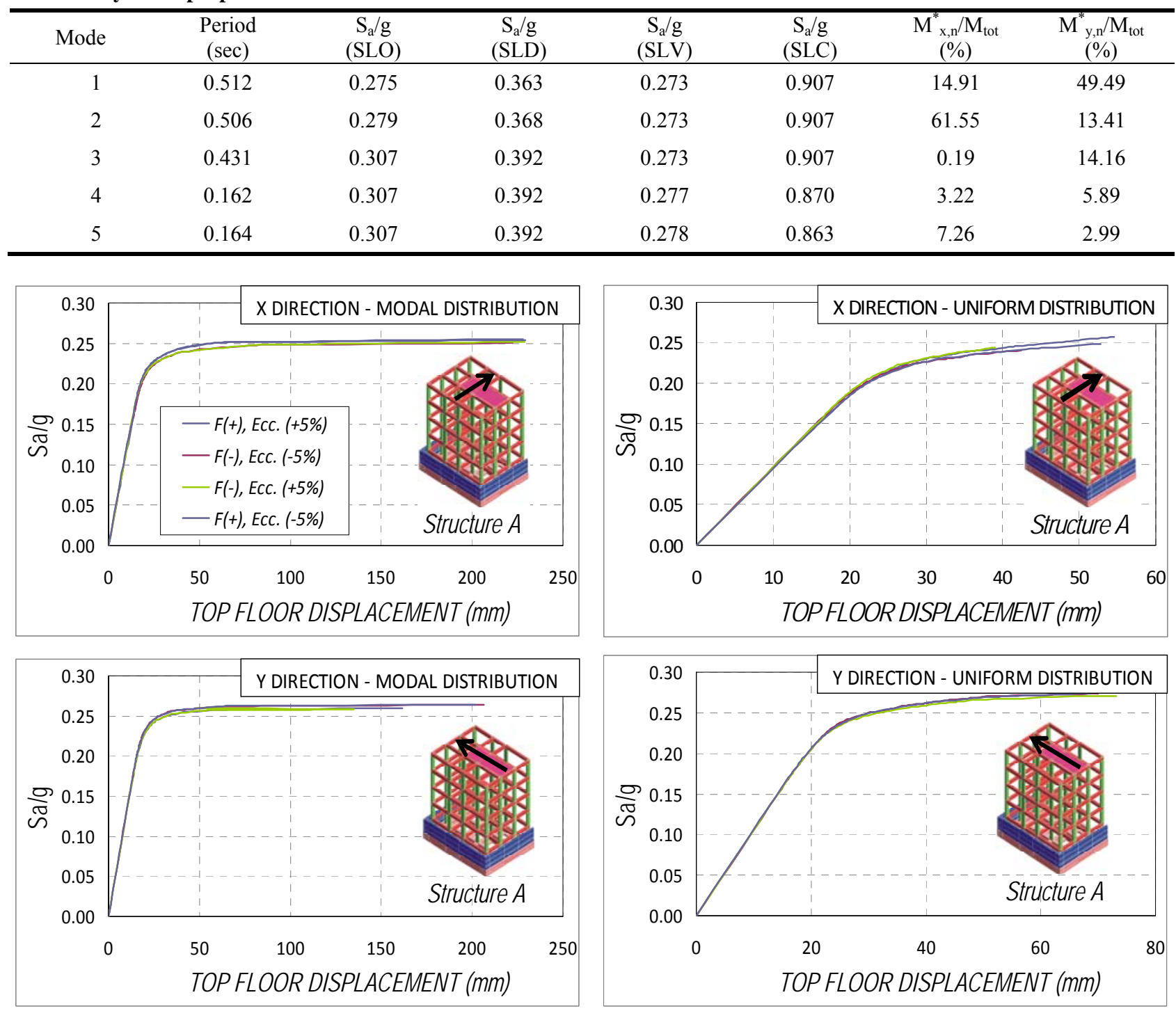

Fig. 3a Capacity spectra of structure A. Variation with direction and distribution of lateral forces and with accidental eccentricity.

In Table 5 the minimum values of peak ground acceleration for different limit states and the corresponding values of risk index are reported. The results obtained show that many verifications, for the operationally limit state (all the structures), for the damage limit state (Structure C) and for the life safety limit state (Structures A, C), are not satisfied. 

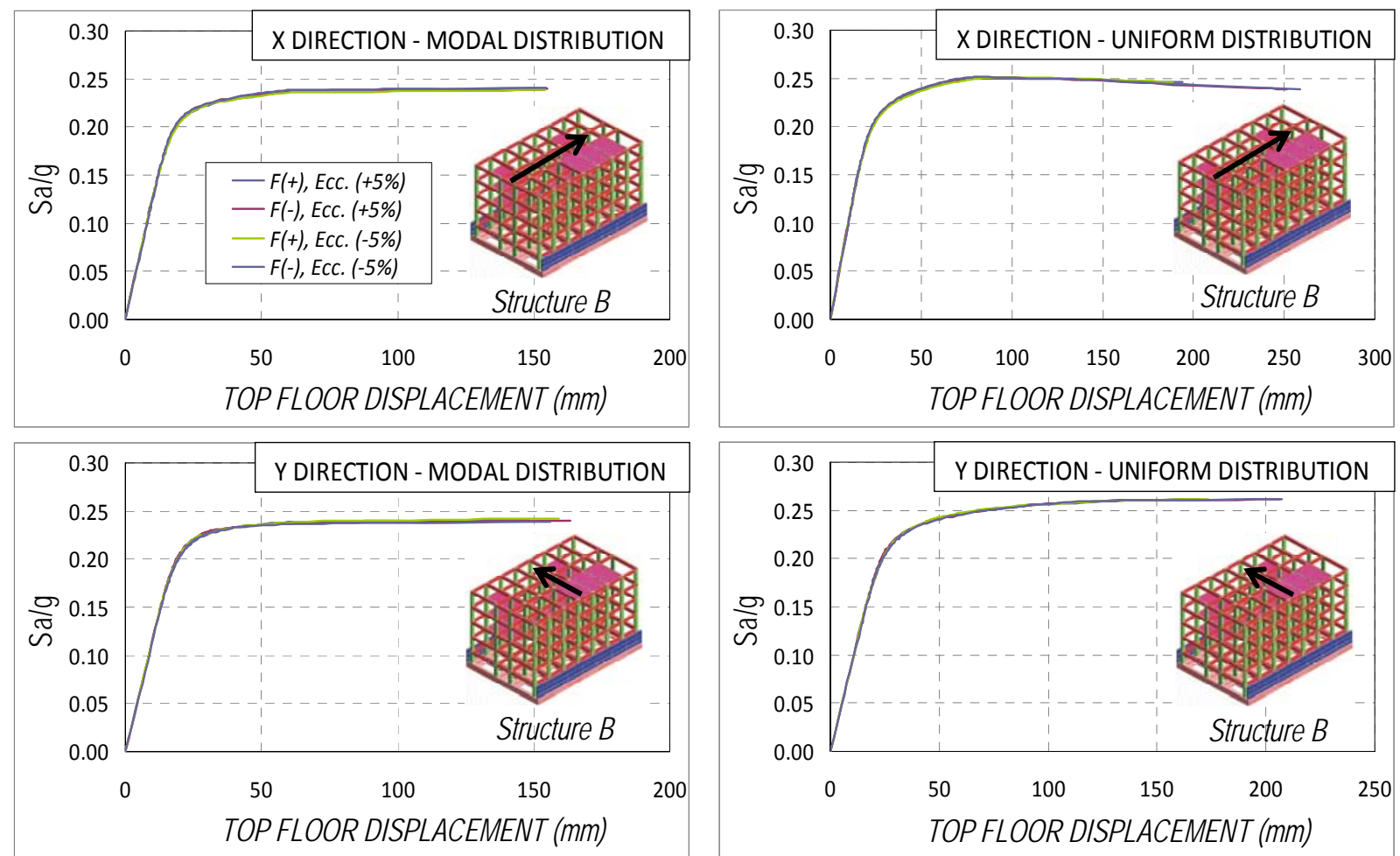

Fig. 3b Capacity spectra of structure B. Variation with direction and distribution of lateral forces and with accidental eccentricity.
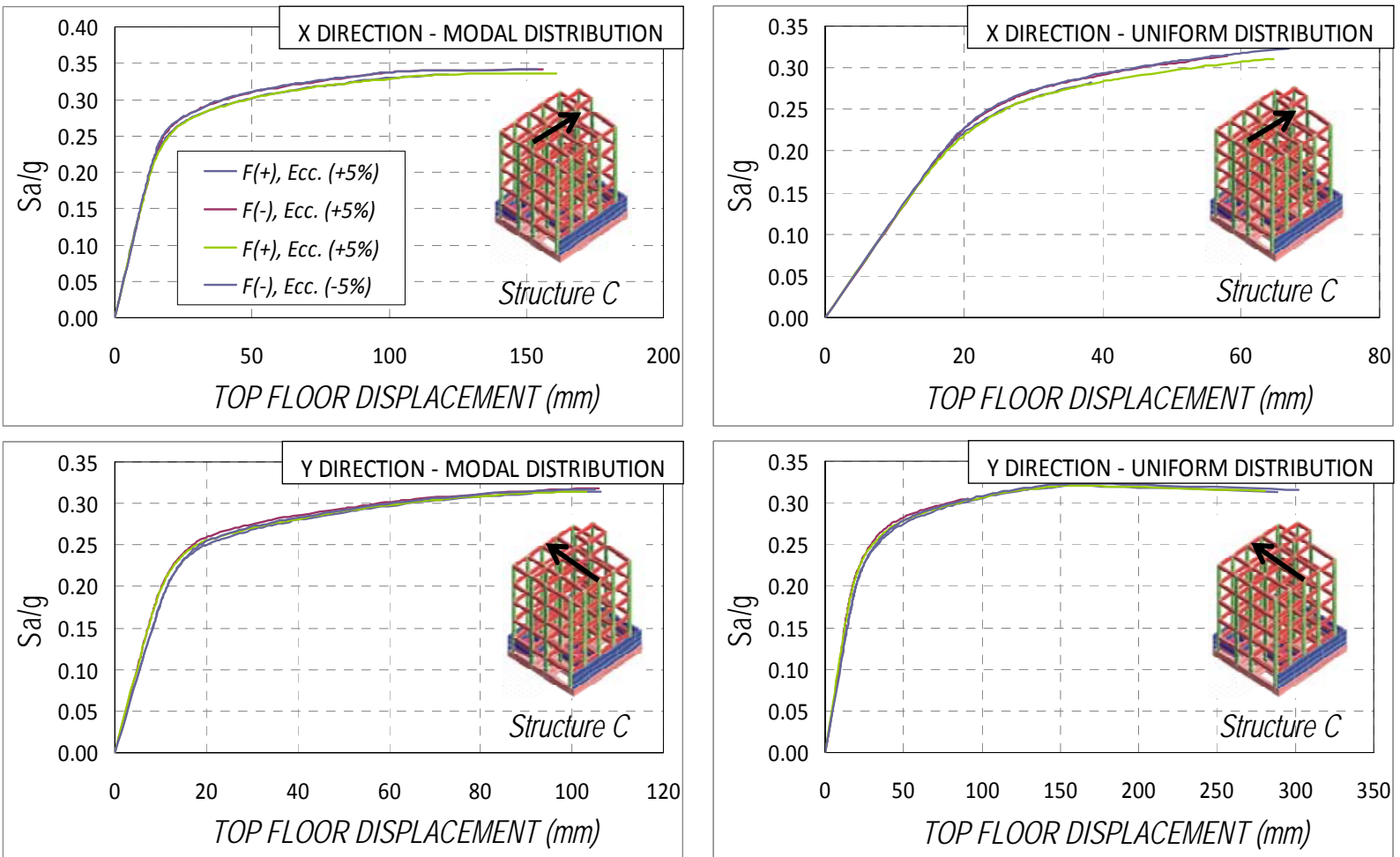

Fig. 3c Capacity spectra of structure C. Variation with direction and distribution of lateral forces and with accidental eccentricity. 
Table 5 Peak ground acceleration and risk index for different Limit States (SLO, SLD, SLV, SLC).

\begin{tabular}{ccccccccc}
\hline Structure & $\mathrm{PGA}_{\mathrm{SLO}}^{\mathrm{c}} / \mathrm{g}$ & $\mathrm{PGA}_{\mathrm{SLD}}^{\mathrm{c}} / \mathrm{g}$ & $\mathrm{PGA}_{\mathrm{SLV}}^{\mathrm{c}} / \mathrm{g}$ & $\mathrm{PGA}_{\mathrm{SLC}}^{\mathrm{c}} / \mathrm{g}$ & $\alpha_{\mathrm{SLO}}$ & $\alpha_{\mathrm{SLD}}$ & $\alpha_{\mathrm{SLV}}$ & $\alpha_{\mathrm{SLC}}$ \\
\hline $\mathrm{A}$ & 0.087 & 0.161 & 0.188 & 0.176 & 0.802 & 1.157 & 0.550 & 0.510 \\
$\mathrm{~B}$ & 0.084 & 0.149 & 0.345 & 0.345 & 0.775 & 1.068 & 1.085 & 1.000 \\
$\mathrm{C}$ & 0.087 & 0.135 & 0.190 & 0.190 & 0.802 & 0.971 & 0.598 & 0.552 \\
\hline
\end{tabular}

\section{Seismic Retrofit}

\subsection{Base Isolation}

The protection level of the structure and the selection of the retrofit system are the important decisions in the design process. The preliminary evaluation of the existing structures reveals the unsatisfactory seismic behaviour depending on the insufficient lateral capacity and limited ductility, especially for the structures $\mathrm{A}$ and $\mathrm{C}$. To provide the basis for the design decision-making process, it is necessary to evaluate the effect of various retrofit systems on structural performance, to quantify the upgrade of the seismic performance and to select a cost-effective rehabilitation methodology. The rehabilitation strategy must improve the seismic behaviour of the structures. This objective may be pursued by: (1) increasing the ductility of columns, beams and joints; (2) reducing the seismic stresses in the existing frames by providing supplemental vertical-resisting elements; (3) changing the system to a shear wall system by infilling the reinforced concrete frames. Since spectral displacements generally decrease with natural frequency, the increase in stiffness was a very popular approach in the past. However, as stiffness increases also the strength increases leading to larger mechanism forces in non-ductile members, foundations and connectors. Furthermore, the increase of stiffness may change the nonlinear response and produce a period shortening that increases the seismic demand. As a consequence, the strategies based on increase of capacity may have some problems of convergence. Furthermore, attempting to make the existing building comply with the current code provisions may be economically prohibitive. As an alternative, seismic isolation and earthquake mitigation have long been recognized as the two main effective methods to reduce dynamic responses of structures when subjected to earthquake without increasing their global stiffness [8, 9]. In particular, the mechanical dampers may effectively reduce the earthquake input energy. On the other side, base isolation causes the natural period of the structure to increase and results in increased displacements across the isolation level and reduced accelerations and displacements in the superstructure during an earthquake. This not only provides safety against collapse, but also largely reduces damage, which is fundamental for facilities that should remain operational after severe earthquakes such as emergency centres, fire stations and hospitals. The decoupling from the horizontal components of the ground motion is obtained by creating a horizontal layer with high horizontal flexibility between the superstructure and the foundation. The retrofit is realized connecting the first floor of the three structures to have one only isolation plane (Figs. 4-5). The isolation system is composed of 25 High Damping Rubber Bearings (16 FIP SI-S 800/180 and 9 FIP SI-S 650/180 with design displacement of $350 \mathrm{~mm}$ ) and free Sliding Devices (pot-type bearings - Vasoflon series). Table 6 provides the geometrical and mechanical properties of the isolation devices (diameter $\mathrm{D}$, effective stiffness $\mathrm{K}_{\mathrm{e}}$, vertical stiffness $\mathrm{K}_{\mathrm{v}}$, axial force capacity $\mathrm{N}_{\mathrm{SLU}}$, primary shape factor S1, secondary shape factor S2). Table 7 gives the dynamic properties of the isolated structure (modal period and damping ratio $\xi$, spectral acceleration at various limit states, modal mass ratios $\mathrm{M}_{\mathrm{x}, \mathrm{n}}^{*} / \mathrm{M}_{\mathrm{tot}}$ and $\left.\mathrm{M}_{\mathrm{y}, \mathrm{n}}^{*} / \mathrm{M}_{\mathrm{tot}}\right)$.

\subsection{Rehabilitation of Structural Members}

The basis idea for seismic isolation of the building is to reduce the seismic forces by a suitable selection of 
Table 6 Geometrical and mechanical characteristics of isolators.

\begin{tabular}{ccccccc}
\hline Type & $\mathrm{D}(\mathrm{mm})$ & $\mathrm{K}_{\mathrm{e}}(\mathrm{kN} / \mathrm{mm})$ & $\mathrm{K}_{\mathrm{v}}(\mathrm{kN} / \mathrm{mm})$ & $\mathrm{N}_{\mathrm{SLU}}(\mathrm{kN})$ & $\mathrm{S}_{1}$ & $\mathrm{~S}_{2}$ \\
\hline SI-S 650/180 & 650 & 0.74 & 854 & 6260 & 17.5 & 3.50 \\
SI-S 800/180 & 800 & 1.12 & 1506 & 13280 & 19.5 & 4.33 \\
\hline
\end{tabular}

Table 7 Dynamic characteristics of isolated structure.

\begin{tabular}{ccccccccc}
\hline Mode & Period $(\mathrm{sec})$ & $\xi(\%)$ & $\mathrm{S}_{\mathrm{a}} / \mathrm{g}(\mathrm{SLO})$ & $\mathrm{S}_{\mathrm{a}} / \mathrm{g}(\mathrm{SLD})$ & $\mathrm{S}_{\mathrm{a}} / \mathrm{g}(\mathrm{SLV})$ & $\mathrm{S}_{\mathrm{a}} / \mathrm{g}(\mathrm{SLC})$ & $\mathrm{M}_{\mathrm{x}, \mathrm{n}}^{*} / \mathrm{M}_{\mathrm{tot}}(\%)$ & $\mathrm{M}_{\mathrm{y}, \mathrm{n}}^{*} / \mathrm{M}_{\mathrm{tot}}(\%)$ \\
\hline 1 & 3.020 & 15 & 0.032 & 0.044 & 0.100 & 0.112 & 0.00 & 99.98 \\
2 & 3.014 & 15 & 0.032 & 0.044 & 0.100 & 0.112 & 99.99 & 0.00 \\
3 & 2.265 & 15 & 0.056 & 0.078 & 0.198 & 0.214 & 0.00 & 0.01 \\
4 & 0.397 & 5 & 0.307 & 0.392 & 0.853 & 0.907 & 0.00 & 0.00 \\
5 & 0.394 & 5 & 0.307 & 0.392 & 0.853 & 0.907 & 0.00 & 0.00 \\
6 & 0.355 & 5 & 0.307 & 0.392 & 0.853 & 0.907 & 0.00 & 0.00 \\
\hline
\end{tabular}
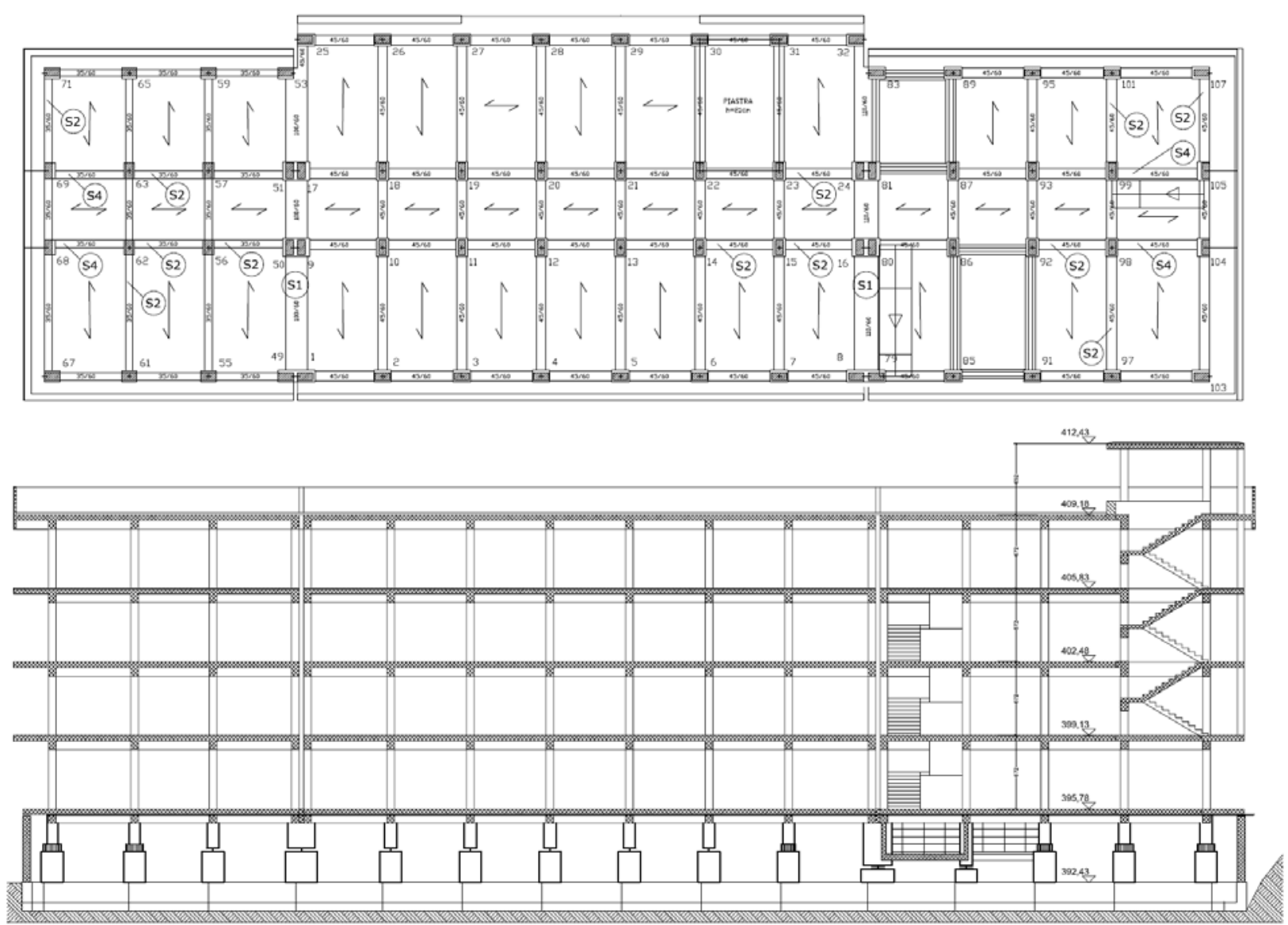

Fig. 4 Plan view and section view of the hospital building in Avellino (Italy).

the vibration period of the structure. As a consequence, only a very limited number of structural members required strengthening interventions. The rehabilitation strategy included the increase of strength capacity in first floor columns and in few beams in elevation (Figs. 4-7).
Concrete strengthening is realized through jacketing existing columns with added confining cover concrete, steel bars and stirrups and through beton plaqué of some beams. Removal of cover concrete for modification of existing reinforcement details should avoid damage to core concrete and to the bond between 
ISOLATION DEMCE FIP SI-S 800/180 — SLIDING DEMCE FP Vasoflon VM 200/700/700 ¿… SLIDING DEMCE FIP Vasoflon 2x VM 200/700/700 - ISOLATION DEVCE FIP SI-S 650/180 I SLIDING DEMCE FP Vasoflon VM 350/700/700

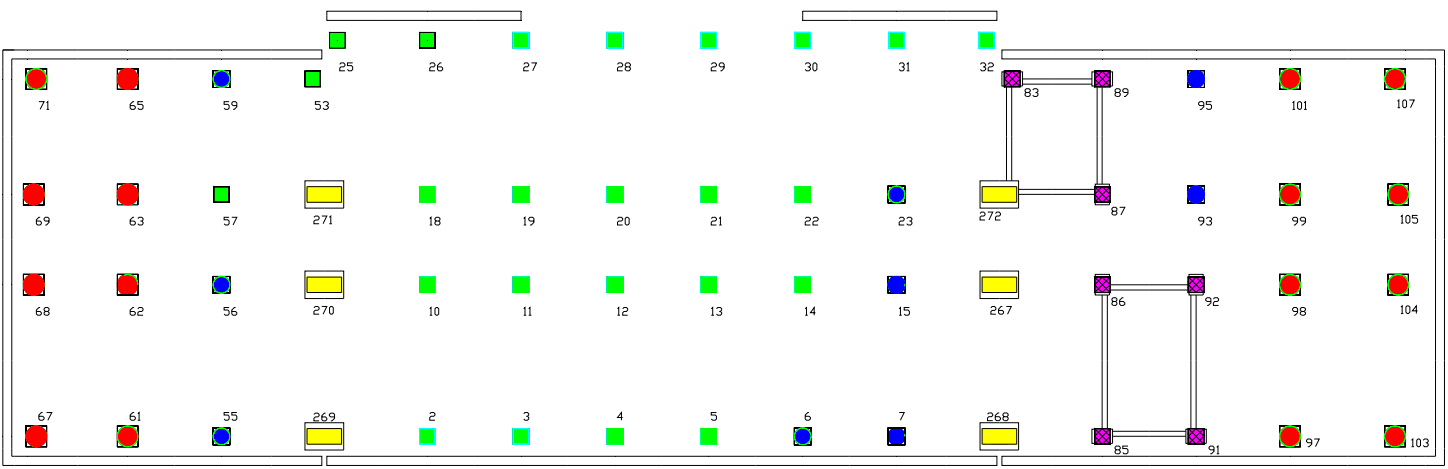

Fig. 5 Plan view of isolation system.

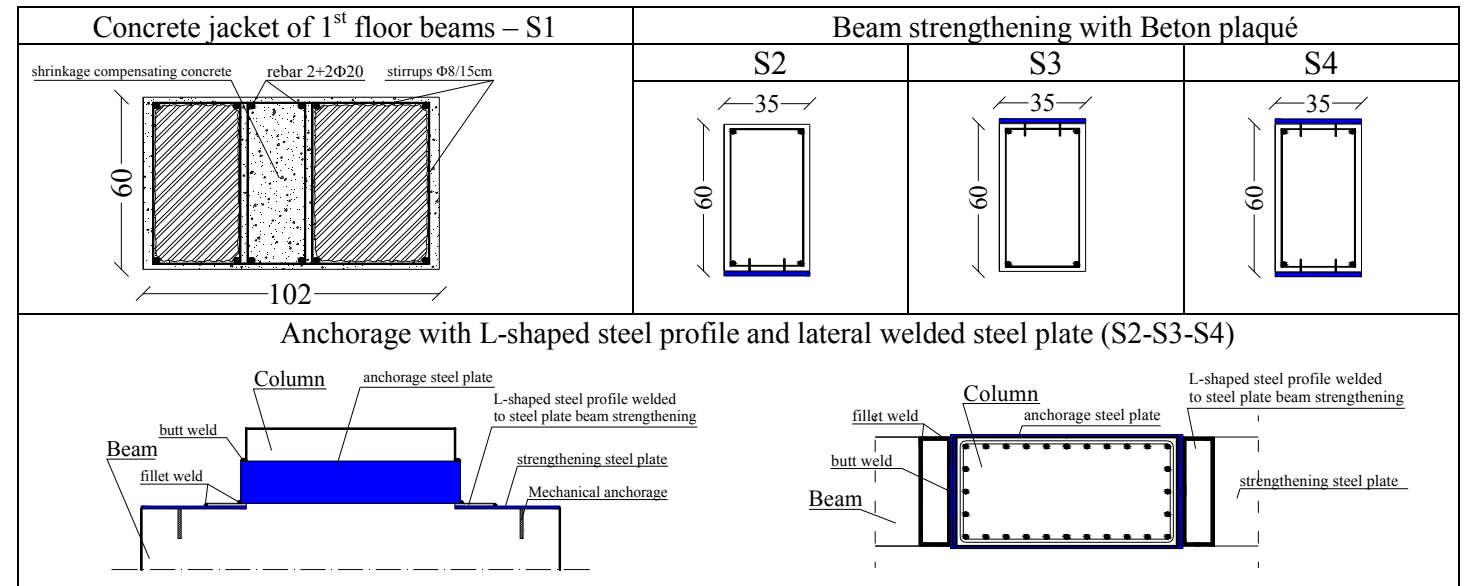

Fig. 6 Strengthening of structural members.

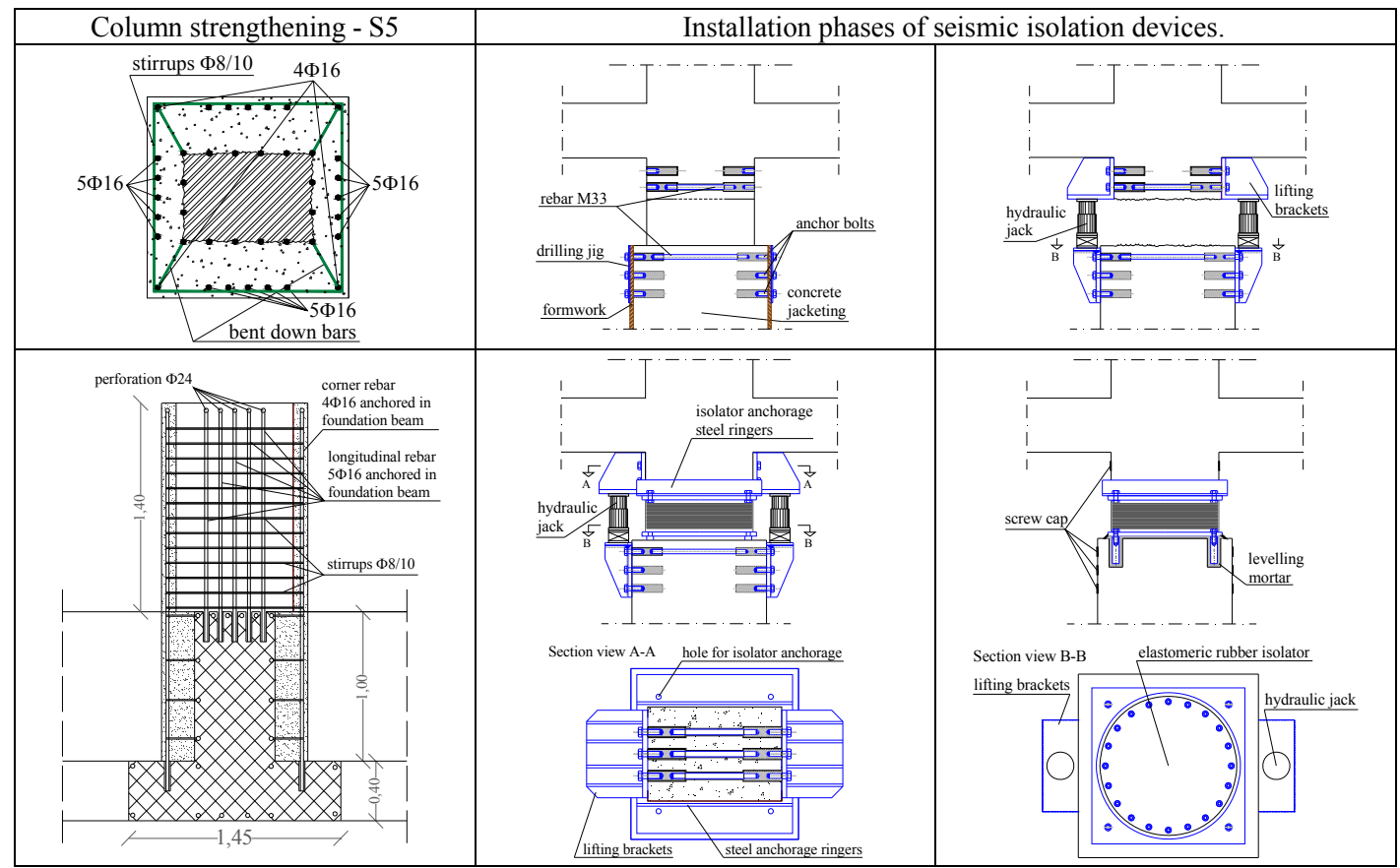

Fig. 7 Strengthening of structural members. Installation of the rubber isolation devices (courtesy of FIP group). 
existing reinforcement and core concrete. In Fig. 7 some of the installation phases of seismic isolation devices are shown. The columns will be temporarily propped on two hydraulic jacks, the sections of columns will be cut out at this level and, finally, the rubber bearings will then be inserted.

\section{Seismic Response of Isolated Hospital Building}

The nonlinear dynamic response is usually obtained by direct integration methods of the equations of motion. This conventional approach requires the solution of a system of differential equations whose size is equal to the total number of degrees of freedom of the isolated structure. As an alternative, the complex mode superposition can give several advantages for the evaluation of seismic response of isolated structures, and it was found to be competitive in terms of computational effort with direct integration methods [10]. On the other side, the isolated structures have a very limited number of points in which nonlinear behaviour takes place when subjected to seismic loading. In this case, the Wilson Fast Nonlinear Analysis (FNA) Method [11] based on an iterative vector superposition algorithm is extremely efficient, and it has demonstrated significant reductions in processing times when compared with other nonlinear analysis methods. In this paper, the seismic response was evaluated using: (1) Linear Dynamic Analysis (LDA); (2) Nonlinear Response History Analysis (RHA); (3) Fast Nonlinear Analysis (FNA). In order to demonstrate the effectiveness of seismic isolation to avoid the yielding in the superstructure, both linear and nonlinear models were used for the structure in elevation. In particular, a Fiber PMM hinge model was implemented in SAP 2000 computer program (Fig. 8).

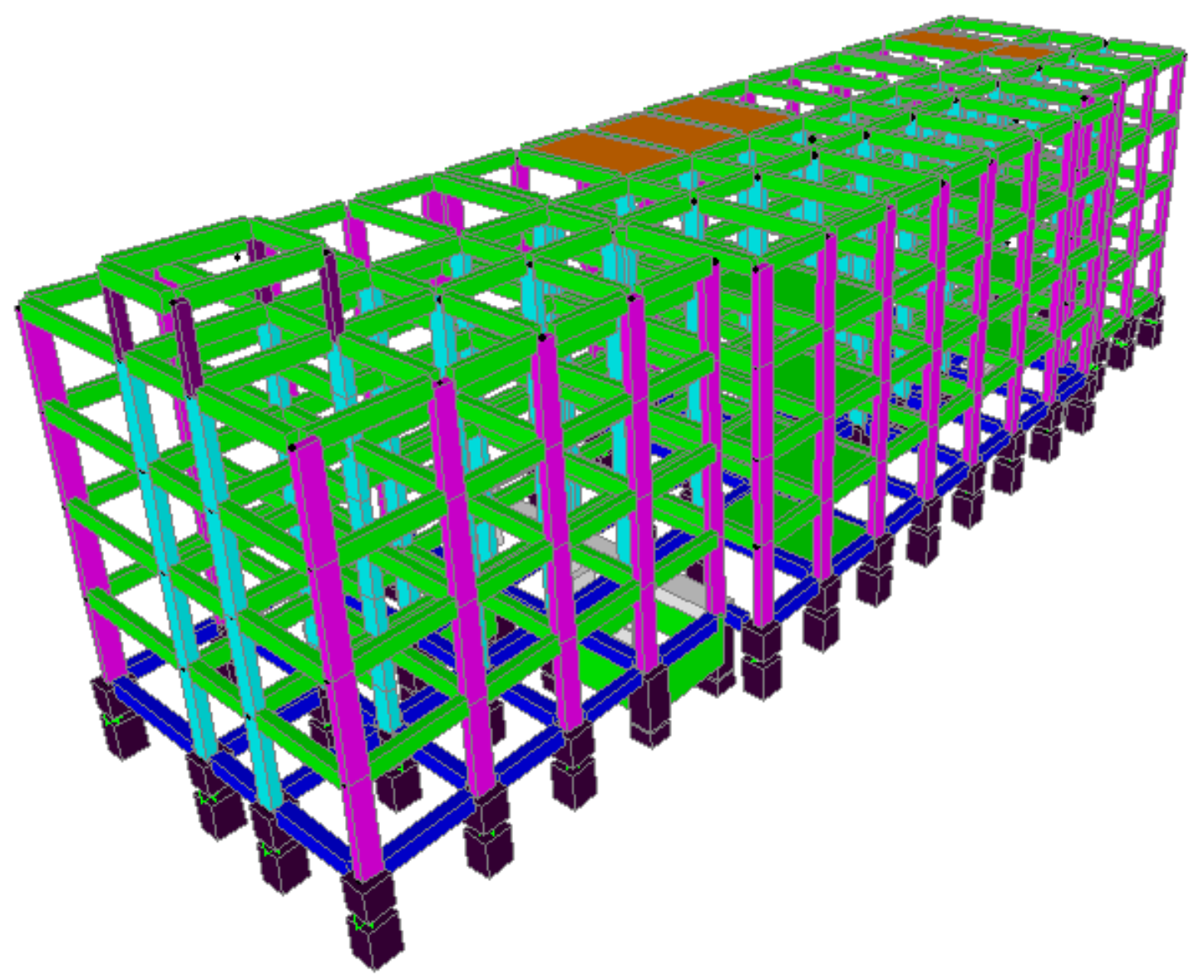

Fig. 8 Structural model of isolated structure. 
The Fiber PMM hinge model is a multi-axial spring model that is used for reproducing the behaviour of flexural and axial deformation of column element and for representing the interaction among bi-directional bending moments and axial load. The hysteretic restoring force of the isolation device is approximated by the well known Bouc-Wen model [12]. A set of 10 accelerograms typical of strong ground motions recorded in soil sites type $B$ were used in the analyses (Table 8). The earthquakes were scaled to the peak ground acceleration for the Collapse Limit State $\mathrm{PGA}_{\mathrm{SLC}}=0.36 \mathrm{~g}$. In Figs. 9-10 the acceleration and displacement response spectra of these earthquakes is represented. In Fig. 11 the top-bottom relative displacement time history of superstructure and the peak displacement pattern are shown. Elastic model and inelastic model of superstructure give the same results, and this means that seismic isolation is effective to avoid the yielding in the superstructure. In Fig. 12 the results from Fast Non linear Dynamic Analysis (FNA) are compared to nonlinear response history analysis (RHA) and to linear dynamic analysis (LDA) carried out with an equivalent viscoelastic model for the isolation devices. The results evidenced a good correlation between FNA and RHA, while LDA may give very different responses. In Figs. 13-14 the displacement and drift ratio time-histories for an earthquake ground motion in Y-Direction are reported.

Table 8 Parameters of the earthquake ground motions.

\begin{tabular}{ccccccc}
\hline Num. & Cod. & Input & Data & Direction & PGA/g & Magnitudo Body-wave \\
\hline 1 & $181 \mathrm{X}$ & Boshroyeh & 16.09 .78 & EW & 0.102 & 6.4 \\
2 & $293 \mathrm{X}$ & Rionero in Vulture & 23.11 .80 & EW & 0.099 & 6.0 \\
5 & $302 \mathrm{Y}$ & Lauria & 23.11 .80 & NS & 0.016 & 6.0 \\
6 & $335 \mathrm{Y}$ & Korinthos & 25.02 .81 & NS & 0.120 & 5.7 \\
7 & $353 \mathrm{Y}$ & Balikesir & 05.07 .83 & NS & 0.015 & 5.5 \\
8 & $477 \mathrm{X}$ & Tehran & 20.06 .90 & EW & 0.033 & 6.2 \\
9 & $477 \mathrm{Y}$ & Tehran & 20.06 .90 & NS & 0.029 & 6.2 \\
10 & $480 \mathrm{Y}$ & Tonekabun & 20.06 .90 & NS & 0.088 & 6.2 \\
11 & $499 \mathrm{Y}$ & Akhalkalaki & 29.04 .91 & NS & 0.007 & 6.2 \\
12 & $536 \mathrm{X}$ & Tercan & 13.03 .92 & EW & 0.029 & 6.1 \\
\hline
\end{tabular}

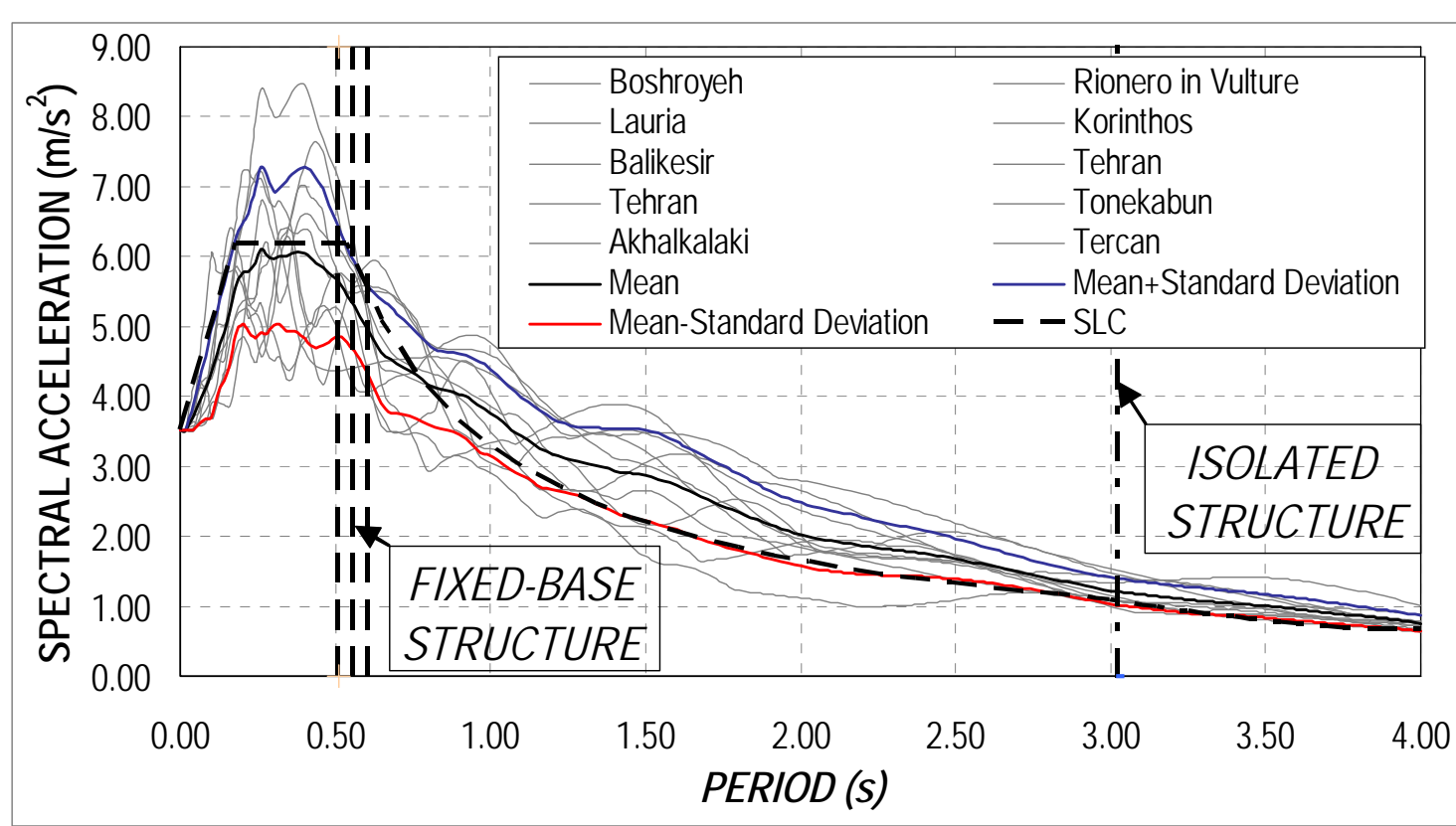

Fig. 9 Acceleration response spectra of the earthquake ground motions and comparison with SLC elastic response spectra. 


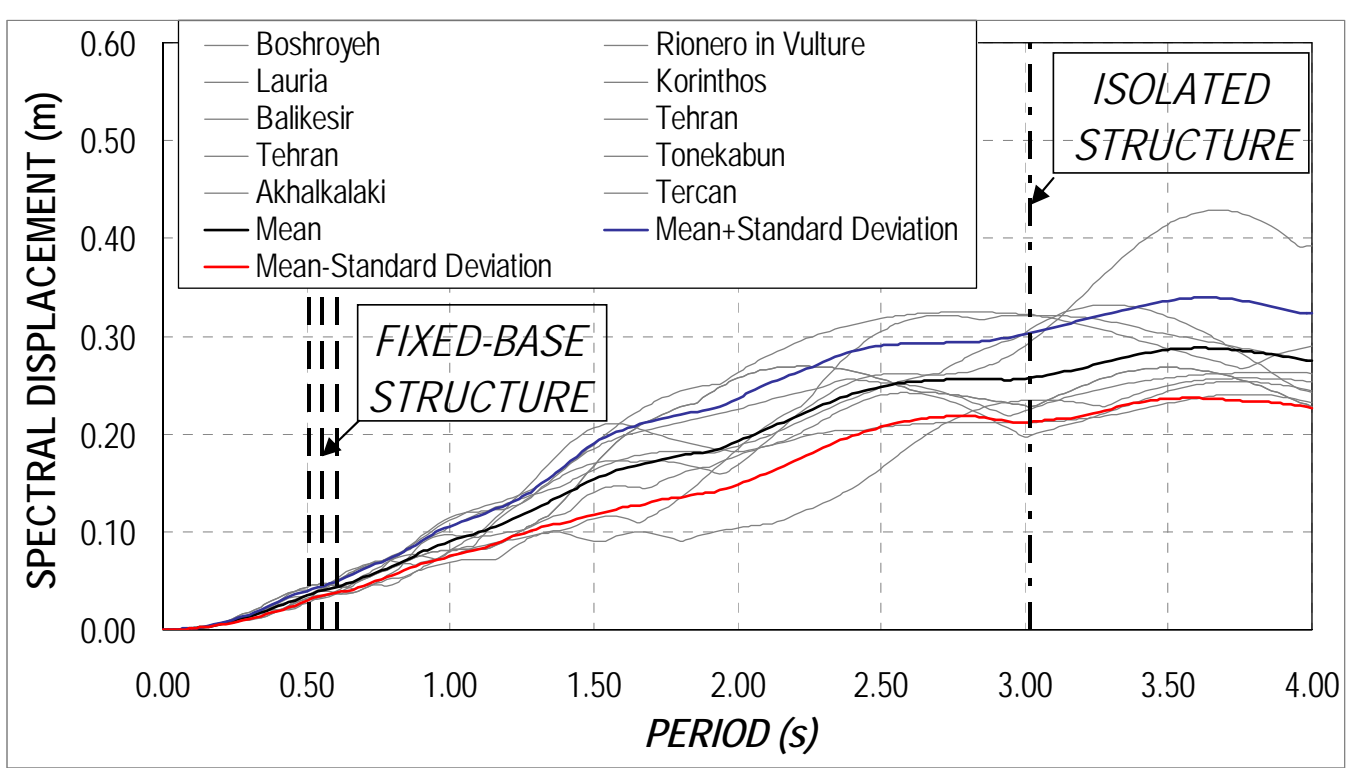

Fig. 10 Displacement response spectra of the earthquake ground motions.
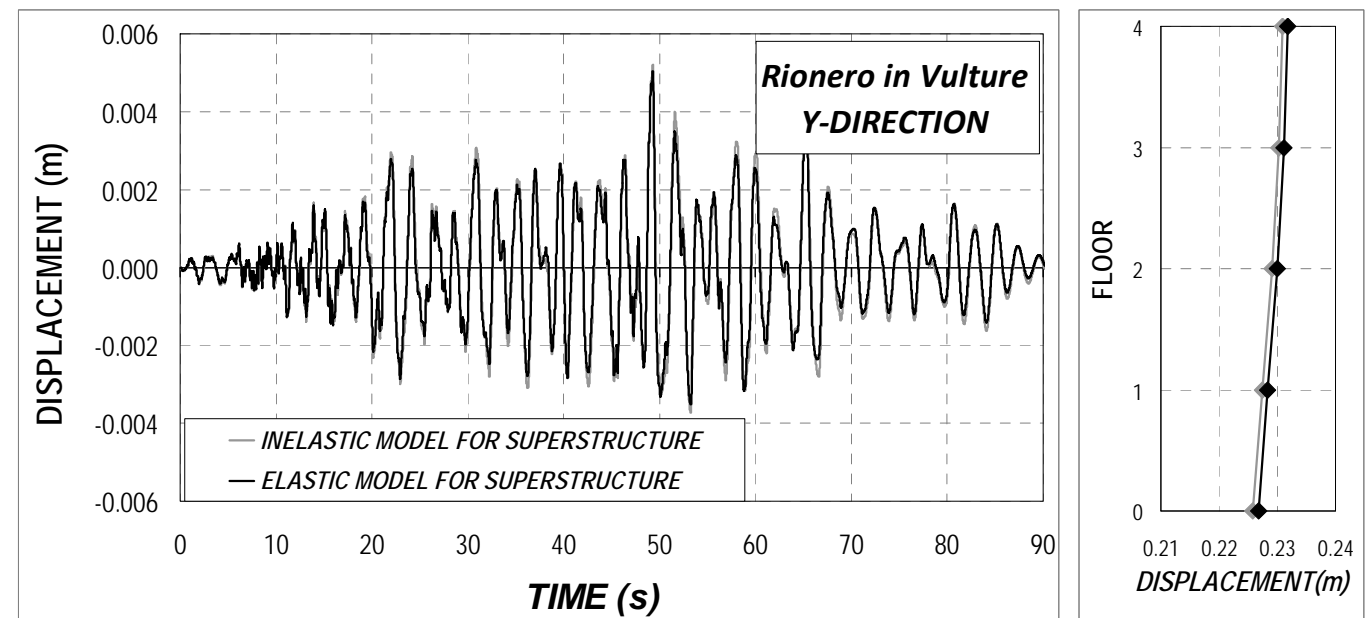

Fig. 11 Top-bottom relative displacement of superstructure, peak displacement pattern, comparison between elastic and inelastic model of superstructure.

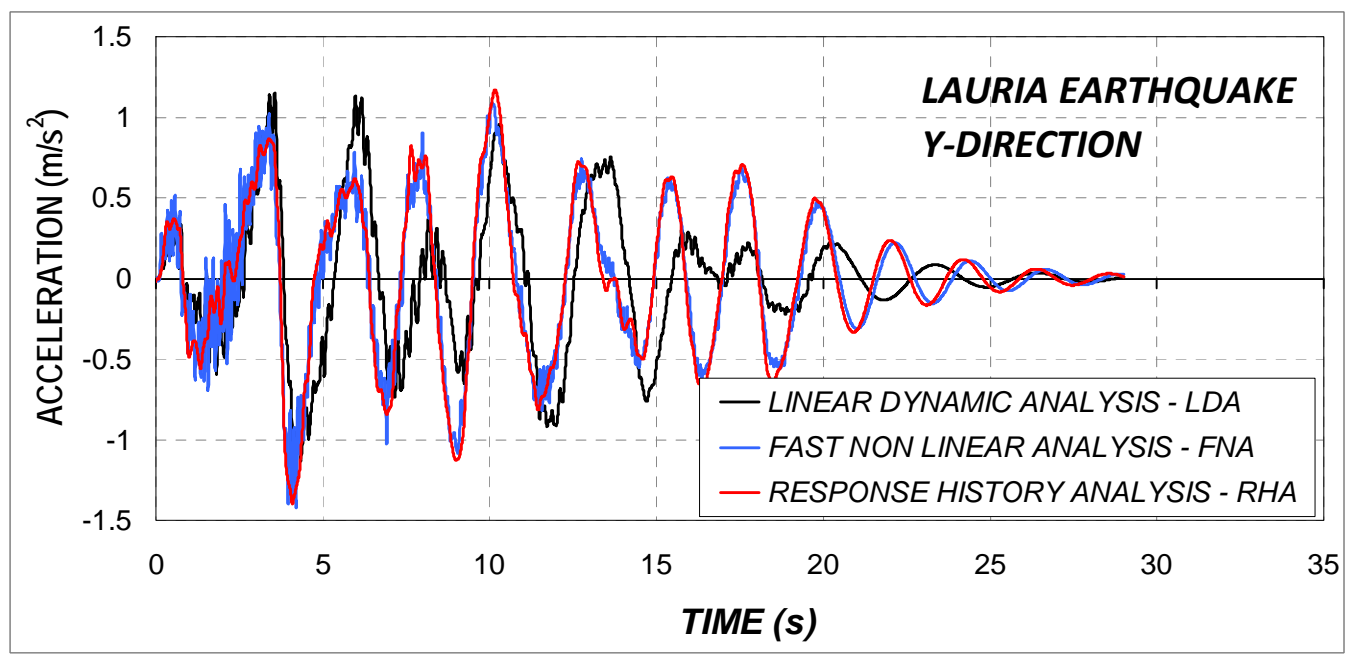

Fig. 12 Top-floor acceleration time-history: Y-Direction. 


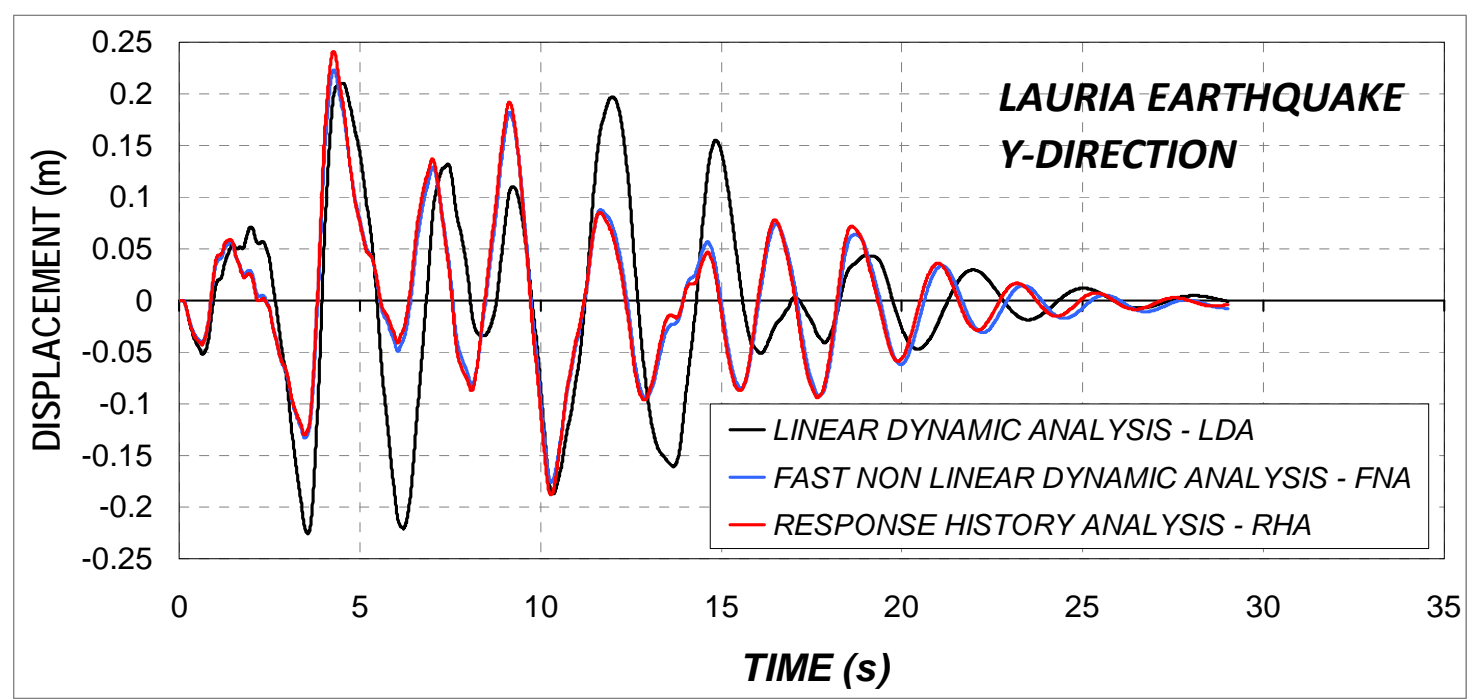

Fig. 13 Top-floor displacement time-history: Y-Direction.

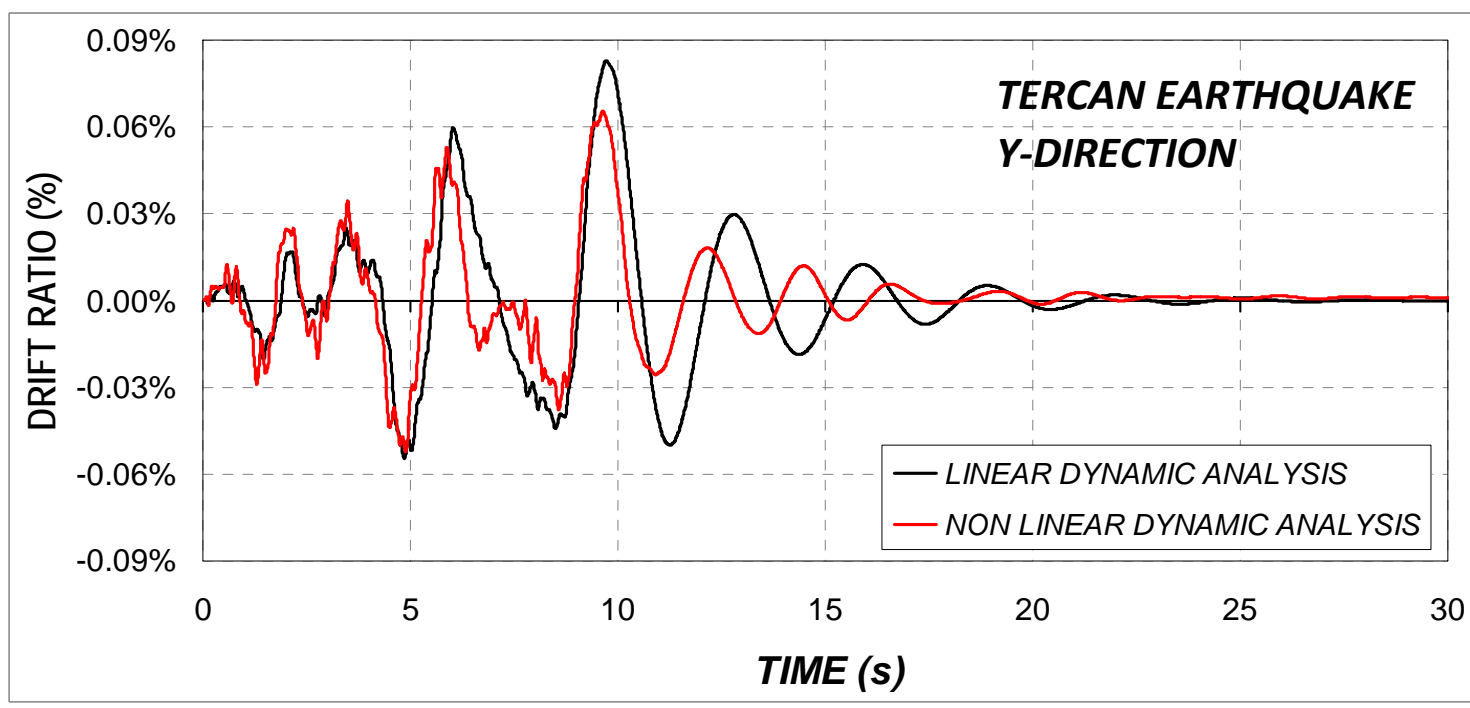

Fig. 14 Drift Ratio time-history (storey 1-2): Y-Direction.

The results evidenced small accelerations and displacements in the superstructure during the earthquakes. Furthermore, a great reduction of the interstorey drift also for the Collapse Limit State is produced by seismic isolation. In particular, the maximum interstorey drift ratio is $0.0829 \%$ that is only $16.6 \%$ of limit value of interstorey drift for buildings having non-structural elements of brittle materials (drift $0.5 \%$ for the Damage Limit State).

\section{Conclusions}

The paper deals on a significant retrofit project currently under construction of an existing hospital building in Avellino (Italy). At first, preliminary assessment of the seismic vulnerability and identification of the specific deficiencies of the existing building was carried out. The seismic risk assessment evidenced some deficiencies especially for the Operationally Limit State and for the Life Safety Limit State. The base isolation system with rubber isolation bearings and sliding devices proved to be effective in reducing the seismic forces and in limiting the rehabilitation interventions required for the structural members. Finally, the seismic performance of the base-isolated structure was carried out using non linear dynamic analysis. The results obtained showed the 
effectiveness of isolation system to guarantee the limitation of acceleration and interstorey drift and so to ensure that hospital facilities would remain operational after very strong earthquake ground motions.

\section{Acknowledgments}

The authors express their personal appreciation of the valuable assistance given them in the construction site by Fabio Formato (Design Engineer), Giovambattista Aquilino Musto (Construction Manager), Sergio Casarella (Testing Manager), Vincenzo Botticelli (Technical Manager of MUCAFER Enterprise) and FIP Group. Many thanks also to Raffaele Costanzo (Structural Engineer) for the support in modelling.

\section{References}

[1] Italian Code, D.M. 14.01.08, G.U. No.9 - 04.02.08 (in Italian), 2008.

[2] Eurocode 8, Design of Structures for Earthquake Resistance - Part 1: General rules, seismic actions and rules for buildings, European Standard EN 1998-1-2004, Comité Europèen de Normalisation, Bruxelles, Belgium, 2004.

[3] Eurocode 8, Design of Structures for Earthquake Resistance - Part 3: Assessment and retrofitting of buildings, European Standard EN 1998-3-2005, Comité Europèen de Normalisation, Bruxelles, Belgium, 2005.
[4] SAP2000 Advanced Version 14.0, Analysis Ref. Manual, Computer and Structures, Berkeley, CA, 2010.

[5] ATC-40, Seismic evaluation and retrofit of concrete buildings, Report No. ATC-40, Applied Technology Council, Redwood City, CA, 1997.

[6] Ordinance 3274, First Elements Concerning General Criteria for the Seismic Classification of the National Territory and for Technical Norms for Constructions in Seismic Zones, G.U. 8 May 2003 (in Italian).

[7] FEMA 440, Improvement of nonlinear static seismic analysis procedures, prepared by the Applied Technology Council (ATC-55 Project), published by the Federal Emergency Management Agency, Washington, D.C., 2005.

[8] T. E. Kelly, Base Isolation of Structures: Design Guidelines, Holmes Consulting Group Ltd., Wellington, New Zealand, 2001.

[9] R. I. Skinner, W. H. Robinson and G. H. McVerry, An Introduction to Seismic Isolation, John Wiley \& Sons Ltd, Chichester, West Sussex, UK, 1993.

[10] P. Malangone, M. Ferraioli, A modal procedure for seismic analysis of non-linear base-isolated multistorey structures, Earthquake Engineering and Structural Dynamics 27 (4) (1998) 397-412.

[11] P. Leger, E. L. Wilson and R. W. Clough, The Use of Load Dependent Vectors for Dynamic and Earthquake Analyses, Report UCB/EERC-86/04, Berkeley University, 1986.

[12] Y. K. Wen, Method for random vibration of hysteretic systems, Journal of the Engineering Mechanics Division 102 (1976) 249-326 